\title{
On quantitative determination of earthquake risk
}

\author{
A. G. Gilayopolizos
}

Ricevuto il 26 Febbraio 1968

SUMMARY. - A method is proposed for the calculation of a comparable measure of the earthquake risk from the coefficient $a^{*}$ of the $N(. M)$. relation normalized to a standard slope $b$, and a standard area. In comparing the earthquake risk in Greece and southern California, it was found that the average and the maximum earthquake risk in the area of (ireece is about one half and two times, respectively, the average earthquake riski in Southern California.

Another method is proposed for the calculation of the recurrence rates for earthquakes of a given magnitude range in small areas for which the existing earthquake magnitude data are not abundant and good enough for determining a reliable recurrence curve. In view of the large fluctuation of the actual recurrence rates for earthquakes of a given magnitude - - disregarding the accuracy of the avalable data - mapping in the form of the earthquake frequency isolines seems to be meaningless for engineering purposes.

Russuxto. - Servendosi del coefficiente $a^{*}$ della relazione $Y(. I I)$ normalizzata, per una inclinazione $b$ standard ed unarea pure standard, $P$. ha studiato un metodo per la deteiminazione del rischio sismico relativo a diverse tegroni della Terra; confrontando, p. e., la Grecia con la California Meridionale, è stato trovato che il rischio medio e quello massimo della prima regione è di una volta e mezzo-due volte quello della seconda.

Tiene poi proposto un altro metodo per calcolare i periodi di ricor. renza di terremoti. la cui magnitudo sia compresa enco dati valori. ave. nuti in piceole zone per le quali i dati della magnitudo del terremoto stesso, non sono molto numerosi né abbastanza buoni per traceiare unatemdibile curva della ricorrenza.

Vista la grande gamma nella quale variano i periodi della ricorrenza attuale per terremoti del tipo suddetto - data la poca precisione cei dati disponibili -. il disegnare una carta geografiea-sismiea nella quale la frequenza dei terremoti è rappresentata da isolinee, potrebbe apparire poco significativo agli effet $i$ dell'edilizia. 


\section{IXTROHECTIOX.}

Investigating the seismicily of some Greek areas and a score of aftershock secquencies in Greece, I was led to the conchusion that the slope of the cumulative curve, $\log Y=a-b M$, depends largely, if not entirely, on the average focal depth of the earthquakes considered Galanopoulos (1,2). Karnik (3) studying the magnitude, frequency and energy of earthquakes in the European area arrived at the surmise that "the observations of Europe facour the hypothesis of regional change of $b$ against of $b=$ const". However, he fomnd that there is " a pronounced tendency for $b$ to decrease with increasing $M$ max. ", and that "indiridual points show a tendency for $b$ to decrease with an increase of $h$ \%. On the other hand, Riznichenco(') assessed a relatively uniform value of $b$ for a variety of world-wide areas, except for the most strong earthquakes of the globe with $y>7 \frac{1}{2}$. Considering that in some regions of the same earthquake comntry the average focal depth is almost the same, but in some others it might be quite different, and that the foci of the great earthquakes of $M>i \quad \%$ have their seat usually below the Moho-discontinnity $\left({ }^{2}\right)$, the two different tendencies for $b$ fomnd by Riznichenco and Karnik might be attributed to the different focal depth of the earthquakes considered. The same argument seems to be valid for the relation between $b$ and the geotectonic structure of the seismic zone.

In a world-wide survey s. Miyamura $\left({ }^{5}\right)$ found high $b$ values of 1.0-1.8 for the Circum-Pacilic and Apide orogenetic zones, including island areas, where the shocks are predominantly shallow, and medium $b$ values of 0.6-0.7 for continental rift zones and platform block zones, where most of the shorks are originated at the bottom or below the botfom of the crust. Change of $b$ with the time and or the number of shocks might be explained by the vertical migration of the earthquake foci (-). There is evidence ( $\left.{ }^{1}\right)$ that for long sample periods there is no marked change of $b$ with the time or the number of shocks. In the case of Matsushiro earthquakes, which is the best case of well observerd earthquakes, "the value of $b$ did not change significantly with respect to different intercals of timen. According to K. Hamara and T. Hagiwara $\left({ }^{6}\right)$, it is very interesting that the value of $b=0.85$ obtained for the Matsushiro abnormally high activity in the whole period "was similar to that for the general seismic activity". In a detailed study of the aftershocks and microaftershocks of the great 
Alaska earthquake of $1964 \mathrm{R}$. Page $\left({ }^{7}\right)$ was led to the conclusion "that the distribution of microaftershocks with respect to magnitude follous the Gutenberg-Richter magnitude-frequency relationship with a $b$ of 0.8 to 0.9, and that the distribution is constant in space and stationary in time over intervals from a few days to several months". Considering that the strength and the homogeneity of the rocks at a given range of depths presumably must be everywhere about the same, the assumption of $b=$ const. for shallow shocks does not conflict with published data of laboratory experiments $\left({ }^{8}\right)\left({ }^{9}\right)$.

\section{METHOD APPLIED.}

In comparing the earthquake activity in different regions we must consider all earthquakes irrespective of their focal depth. It is intuitively evident that this does not hold for the calculation of the representative value of the earthquake risk. The earthquake effects depend not merely on the seismic energy released, but also on the depth of the earthquake focus. Consequently, in comparing the earthquake risk in defferent regions we must consider earthquakes of about the same focal depth. Assuming that the slope of the recurrence curve depends entirely on the average focal depth of the earthquakes considered, we may reliably estimate the earthquake risk in the seismic regions from the corresponding recurrence curves normalized to a standard slope and a standard area. To do this, we apply the following procedure.

From the $N(M)$-relation of a given region we first find the magnitude of the shock occurring once per year. After that, we determine the coefficient $a_{1}$ that should have the $N(M)$-relation with a standard coefficient $b$, say 0.80 , in order to get the earthquake magnitude found previously. In the third stage we calculate the coefficient $a^{*}$ that should have the $N(M)$-equation with the standard coefficient for a standard area, say $10.000 \mathrm{~km}^{2}$.

According to V. Karnik $\left({ }^{10}\right)$, the constant a of the magnitudefrequency relation depends " on the period of observation, on the size of the investigated area and on the level of the seismic activity as well". Thus the coefficient $a^{*}$ obtained for one year as a time unit, normalized to a standard slope and a standard area, is a comparable measure of the earthquake risk impending over the seismic regions from earthquakes of about the same focal depth. 
An illustration of the method is given in the following table which shows the earthquake risk impending upon various regions of the Southern California. The data of the first three columms were taken from Table II published by $C$. R. Allen et al (11). The average earthquake risk determined from the normalized cumulative curve of the comntry in question was taken as unit in the last colmmn.

Table I - TIE EARTIQLAKE RISK IMPEXDISG CPOS VARIOLS REGIOXS OF THE SOLTIERX CILIFORNIA

\begin{tabular}{|c|c|c|c|c|c|c|c|}
\hline \multirow[b]{2}{*}{ Region } & \multirow{2}{*}{$\begin{array}{c}\text { Area } \\
k m^{2} \times 10^{3}\end{array}$} & \multirow{2}{*}{$\begin{array}{c}b \\
\text { slope } \\
\text { of eurve }\end{array}$} & \multirow{2}{*}{$\begin{array}{c}\text { "once } \\
\text { per vear" } \\
\text { Farth- } \\
\text { guake } l \text { fl }\end{array}$} & \multicolumn{3}{|c|}{ Coeflicients } & \\
\hline & & & & $a$ & $a_{1}$ & $a^{*}$ & \\
\hline Kern County & 8.45 & 0.80 & 5.3 & 4.24 & 4.24 & 4.31 & $8.1)$ \\
\hline Imperial Valley & $8.6 \overline{5}$ & 0.82 & 5.2 & 4.27 & 4.16 & 4.22 & 6.5 \\
\hline San Bernardino Mts. & 8.49 & 0.85 & 4.8 & 4.08 & 3.84 & 3.91 & 3.2 \\
\hline Owens Valley & 8.101 & 0.82 & 4.2 & 3.44 & 3.36 & 3.45 & 1.1 \\
\hline los Angreles basin & 8.90 & 1.02 & 4.2 & 4.29 & $3.36 j$ & 3.41 & 1.0 \\
\hline San Andreas fault & 8.40 & 0.90 & 3.3 & 2.97 & 2.64 & 2.71 & (). 2 \\
\hline Southern taliformia & 296.10 & $0.86 j$ & (i. 1 & 5.25 & 4.88 & $3 .+1$ & 1.0 \\
\hline
\end{tabular}

The earthquake risk determined by the proposed method is in fair accordance with the grading of the seismic regions appeared in the strain release map of the Sonthern California region, 1934 to $1963\left({ }^{11}\right)$.

The method described above presupposes the existence of earthquake magnitude data abundant and good enough to determine a reliable recurrence curve for the region considered. As a rule the existing data for small areas, even for the very active ones, never fulfil this term. Then since the time series of past earthquakes in small areas contains very few events, the methods developed by Gumbel (12) cannot be applied to estimate the probability of recurrence of extreme earthquakes by studying the distribution of yearly earthquake maxima $\left({ }^{13}\right)$.

A good practice of overriding this handicap is to calculate the cumulative curve of a large seismotectonic mit for which there is adequate data. Then taking into accomnt that the coeflicient $b$ of the recurrence equation found for the seismotectonic unit depends largely on the average focal depth of the earthquakes considered, we may assmme the $b$ constant, i.e. the same even for very small areas 


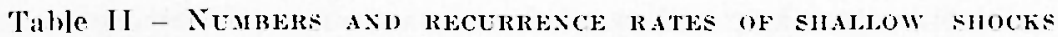
EXPECTED IN TIL AREA OF (IREECE. RECURREXCE EXPECTANCY :

$\log x=-1.43 \pm 0.06-(0.82 \pm 0.02)(8-. Y)$.

SAMPIE PERIOD OF 120 YEARS, $1843-1962$

\begin{tabular}{|c|c|c|c|c|c|c|c|c|c|}
\hline \multicolumn{2}{|c|}{ Magnitudes } & \multicolumn{2}{|c|}{ Sumbers } & \multicolumn{3}{|c|}{ Intervals } & \multicolumn{3}{|c|}{ Recorrence Rates } \\
\hline 01 & Ir greater & $20750 \pm$ & 2850 & per & & Year & 2.5 & \pm 4 & Minmles \\
\hline $11 / 2 n$ & $"$ & $8035 \pm$ & 1105 & $"$ & & $"$ & 1 & $\pm 1 / 4$ & Hours \\
\hline $2 \quad$ & $"$ & $3190=$ & 480 & 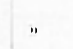 & & $"$ & $2^{3}: 4$ & $\pm 1 / 1$ & " \\
\hline $21 / 20$ & , " & $1225=$ & 165 & $"$ & & $"$ & $71 / 4$ & \pm 1 & $"$ \\
\hline 3 & , " & $475=1$ & 65 & $"$ & & $"$ & $18 \%$ & $\pm 21 / 2$ & $"$ \\
\hline $31 / 2 n$ & $"$ & $185 \pm$ & 25 & $"$ & & $"$ & 2 & $\pm 1 / 4$ & Days \\
\hline $4 \quad$ & , " & $72:$ & & $"$ & & $"$ & 5 & $\pm 3 / 4$ & $"$ \\
\hline $41 / 2 n$ & $"$ & $24 \pm$ & 4 & $"$ & & $"$ & 13 & \pm 2 & $"$ \\
\hline $5 \quad 1$ & $"$ & $11 \pm$ & 2 & $"$ & & $"$ & 1 & $\pm 1 / 3$ & Monthes \\
\hline $51 / 2 "$ & 1 & $21 \pm$ & 3 & $"$ & 5 & Years & 3 & $\pm 1 / 2$ & $"$ \\
\hline $6 \quad 1$ & $"$ & $8=$ & 1 & $"$ & 5 & $"$ & $71 \%$ & \pm 1 & $"$ \\
\hline $61 / 20$ & $"$ & $6 \pm$ & 1 & " & 10 & $n$ & $11 / 2$ & $\pm 1 / 4$ & Years \\
\hline $7 n$ & $"$ & $12 \pm$ & $\underline{?}$ & $"$ & 50 & $"$ & 4 & $\pm 1 / 2$ & $n$ \\
\hline $71 / 2 n$ & " & 810 & 11 & $"$ & 100 & $"$ & $101 \%$ & $\pm 11 / 2$ & $"$ \\
\hline $8 \quad 1$ & " & 310 & 4 & $"$ & 100 & $"$ & 27 & \pm+ & $"$ \\
\hline $81: 21$ & $"$ & 10 & 2 & $"$ & 100 & $"$ & 70 & \pm 10 & $"$ \\
\hline
\end{tabular}

of the unit. Based on this assmmption we divide the seismotectonje mint in small regrions of equal area and substracting the logarithm of the number of the subunits from the coefficient a of the recurrence equation of the seismotectonic mit, we find a recourence equation that would hold for each subunit if the seismic energy released in each of them was the same. Since this is not the case, we proceed in the calculation of the seismic energy released in each subunit in a given period and we find how many times the seismic energy of each subunit is higher or lower than the average seismic energy corresponding to each of them. Then adding the logarithm of the number found for each subunit to the coefficient a of the average recurrence equation of the subunits, we get the coefficient $a_{1}$ holding for each of them. 


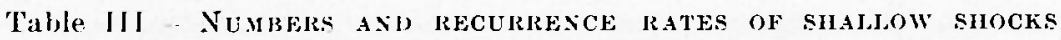

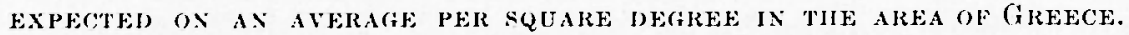
RECURRENCE FXPECTANCY FOR THE WHOLE AREA: $\log N=-1.43 \pm 0.06+(0.82 \pm 0.02)(8-.1)$. SAMPLE PERIOD OF 120 YEARS, $1843-1962$.

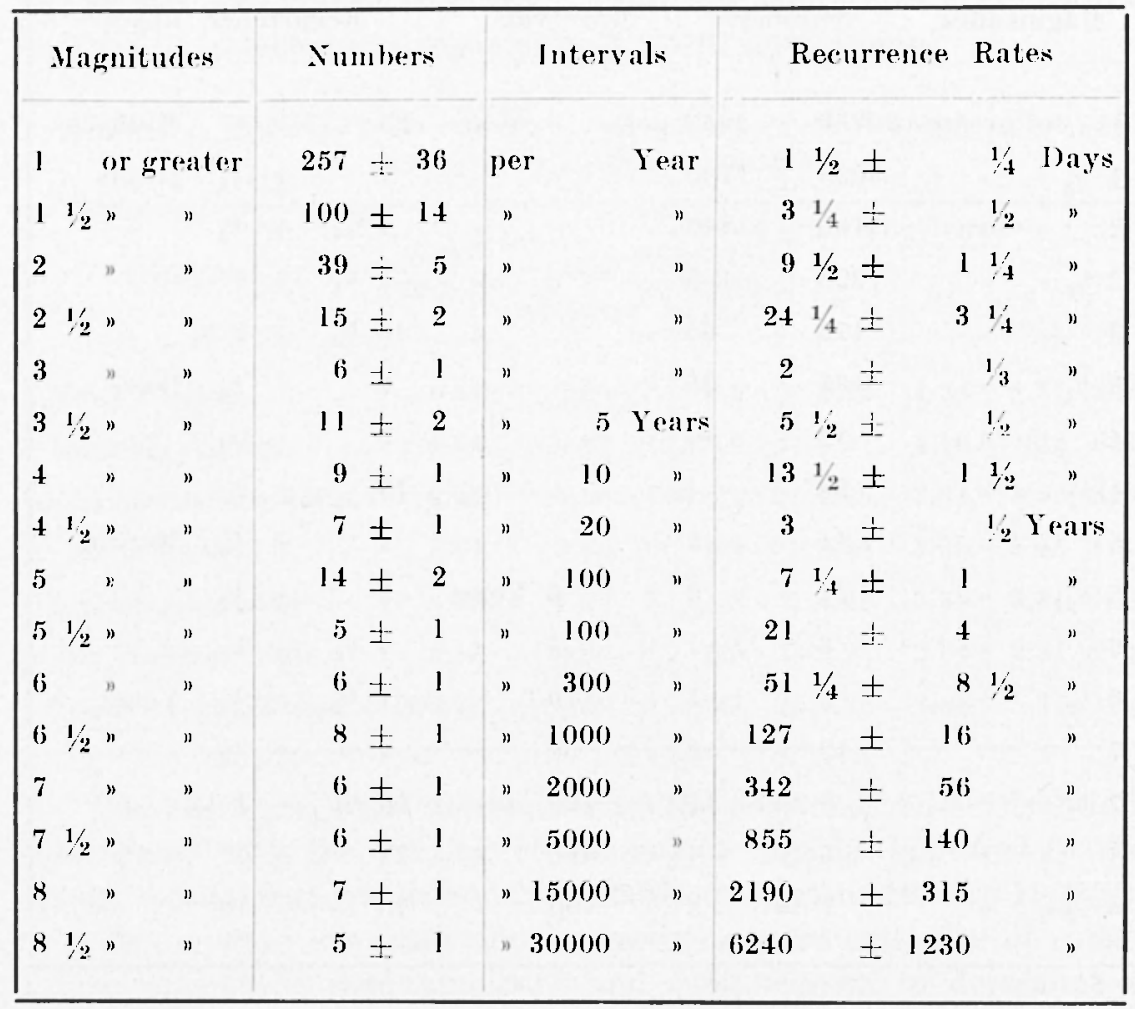

The earthquake risk in each area might be given either in units of the earthquake risk for a standard $b$ in a standard area of a given region taken as prototype, or temptingly by the recurrence rates of the damaging and destructive shocks which are determined from the normalized $N(M)$-relation of the area. The method is simple and practical but not free of the inherent primary hazard in extrapolating long-term activity from relatively short-term records.

The shortcomings of the method, which arise from the short period of the records, i.e. from the small sample, could be more or less wholly removed by increasing the limits of the area. The larger the area, the more representative is the sample. Since the average focal depth of the shallow shocks does not vary noticeably from one 
region to the other and the value of the coefficient $b$ is much dependent on the average focal depth of the shocks considered, the increase of the limits of the area does not affect the roefficient $b$. When the sample consists of shallow shocks only, the small variation of the $b$ value observed from region to region is due a good deal to statistical fluctuation or observational uncertainties (14). On the other hand, we have very many cases of regions considered earthquake immune which recently experienced severe earthquakes. We feel, therefore, that we are more close to the truth, if we consider all regions of the Earth liable to experience earthquakes of whatever magnitude. As a matter of fact, the difference in the seismic behaviom or idiosyncrasy of the various regions arises from the difterence of the corresponding recurrence rates of earthquakes of a given magnitude. The conclusion that comes $u p$ is that the recurrence rates for earthquakes of a given magnitude range make more sense than any other measure of the earthquake risk assigned to seismic regions. Accordingly, several attempts were made to predict return periods for different intensities and predicted intensities for given intervals $\left({ }^{15}, 16,17,18,19\right)$.

Applying the proposed method in the area of Greece, $760.91 \mathrm{~km}^{2}$ $\times 10^{3}$, for which we have found the relation $\log N=5.13-0.82 M$, we derive an average coefficient, for a standard area of $10.000 \mathrm{~km}^{2}$ and a standard slope $0.80, a^{*}=3.13$. In the two centres of higher earthquake activity assessed in the area of Greece the seismic energy released per square degree per 100 years is about $33 / .4$ times the average. Then the coefficient for the two centres is $a^{*}-3.71$. This means, that the average and maximum earthquake risk in the area of Greece is about one half and two times, respectively, the average earthquake risk calculated from the normalized $N(\lambda I)$-relation of Southern California.

The other method of mapping the earthquake risk is that shown in Fig 1. The recurrence rates of shallow shocks in years for a given magnitude drawn in each square degree were calculated as follows.

The whole area of Greece bounded by the $34^{\circ}$ and $42^{\circ}$ latitudes and $19^{\circ}$ and $29^{\circ}$ longitudes consists of 80 square degrees. By subtracting 1.90 , i.e. the logarithm of the number of the square degrees, from the coefficient 5.13 of the relation $\log N-5.13-0.82 \mathrm{~W}$ found for the whole area, we get the relation $\log N=3.23-0.82 \mu$ that would hold for each square degree if the seismic energy released in each of them was the same. Since this is not the rase, we proceed 


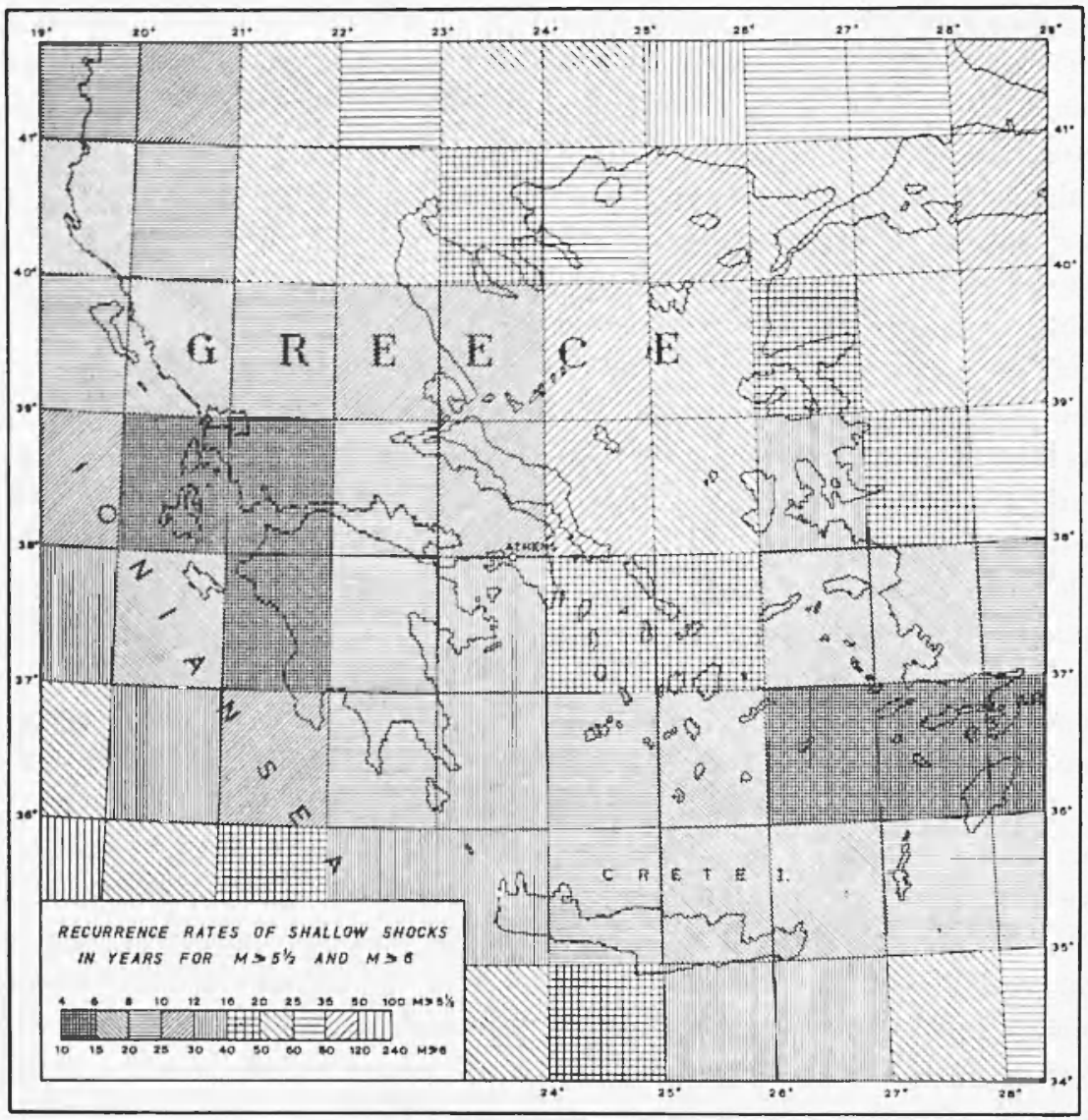

Wig. I - The earthquake risk expressed in recurrence rates for shallow shocks with $. I>5 \%$ and $I I \geqslant 6$ in each square degree of cireece.

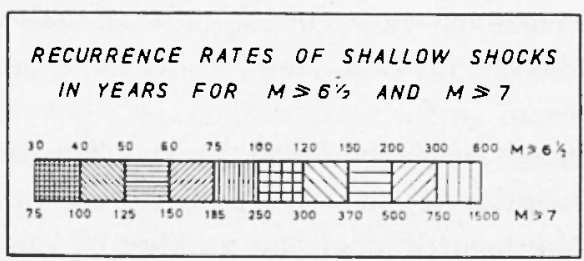

Fig. 2 - Legend referring to Fig. 1.

'l'he cartlequake risk expressed in a similar way in recurrence rates for shallow shocks with $X \geqslant 6 \frac{1}{2}$ and $M>7$ in each square degree of Greece. 
in the calculation of the average seismic energr released per square degree over the given period, 1843-1962, and taking this as unit we alculate the seismic energy released in each square degree over the same period. Then adding the logarithm of the number found for each square degree to the coefficient 3.23 of the average recurrence equation $\log N=3.23-0.82 \mathrm{M}$, we get the individual coeflicient of the recurrence equation holding for each of them.

Suppose that for a given square degree, we found the seismic energy released over the period $1843-1962$ two times the average seismic energy released per square degree in the area of Greece over the same period. By adding 0.30, i.e. the logarithm of the number 2 , to the average coefficient 3.23, we get the coefficient 3.53. Then assuming that the coefficient $0.8 \mathrm{~s}$ holds throughout the area of Greece, the recurrence equation for the corresponding region is $\log N=3.53-0.82 \mathrm{~N}$.

In the calculation of the recurrence rates we accepted that the probable error \pm 0.06 of the coefficient -1.43 of the recurence equation $\log N=-1.43 \pm 0.06+(0.82+0.02)(8-. I)$ calculated for the whole area holds for the individual coefficients fomd for each square degree.

In view of the latge fluctuation of the actual recurrence rates for earthquakes of a given magnitude - disregarding the acruracy of the available data - mapping in the form of earthquake frequency isolines would be meaningless for engineering purposes. Thus, it seems sufficient to draw by appropriate shading the recurrence rates for damaging and destructive earthouakes expected in small regions of the area considered.

\section{Disctession.}

One might argue it would be better to get the standard slope equal to 1.0. In that case the coeflicient $a^{*}$ is equal to the magnitucle of the "once per year" earthquake. However, the choice of the standard slope is of decisive importance for the right determination of the seismic index. An example will illustrate the case.

Gutenberg and Richter $\left.{ }^{(20}\right)$ found the following recurrence equations for the globe:

$$
\begin{array}{ll}
\text { Shallow shocks: } & \log N=6.72-0.90 M \\
\text { Intermediate shocks: } & \log N=8.40-1.2 M \\
\text { Deep shocks: } & \log N=7.70-1.2 M .
\end{array}
$$


By normalizing the equations to the slope 1.0, we get:

$\begin{array}{lll}\text { Shallow shocks: } & \log N=7.46-1.0 M \\ \text { Intermediate shocks: } & \log N=7.00-1.0 M \\ \text { Deep shocks: } & \log N=6.42-1.0 \mathrm{M}\end{array}$

Taking as unit the coefficient 6.42 holding for the deep shocks, we get the following indexes for the earthquake risk:

$\begin{array}{lr}\text { Shallow shocks: } & 11.05 \\ \text { Intermerliate shocks: } & 3.84 \\ \text { Deep shocks: } & 1.00 \text {. }\end{array}$

From these indexes we get that 69.5 per cent of the earthquake risk impending upon the globe comes from shallow shocks, 24 per cent from intermediate shocks, and 6.5 per cent from deep shocks.

If we normalize the equations to the slope 1.4, which holds for the very shallow shocks, we get:

$$
\begin{array}{ll}
\text { Shallow shocks: } & \log N=10.45-1.4 M \\
\text { Intermediate shocks: } & \log N=9.80-1.4 M \\
\text { Deep shocks: } & \log N=8.99-1.4 M .
\end{array}
$$

Taking now as unit the coefficient 8.99 found for the deep shocks, we get the following indexes for the earthquake risk:

$\begin{array}{lr}\text { Shallow shocks: } & 29.0 \\ \text { Intermediate shocks: } & 6.5 \\ \text { Deep shocks: } & 1.0 .\end{array}$

From the new indexes we get that about 79 per cent of the earthquake risk impending upon the globe comes from shallow shocks, almost 18 per cent from intermediate shocks, and nearly 3 per cent from deep shocks. The seismic indexes of the earthquake risk from shallow, intermediate and deep shocks found for the standard slope 1.1 might be compared with the average annual energy release from the corresponding depths. According to B. Gutenberg $\left({ }^{21}\right)$, "nearly 80 per cent of the earthqualie energy is released in the upper $60 \mathrm{~km}$ of the

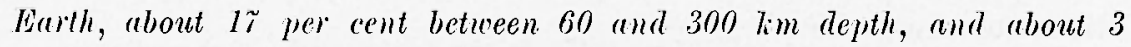
per cent between 300 and $\tilde{\pi} 00 \mathrm{~km}$ ". This points out that the seismologists should sooner or later reach an international agreement for a standard slope in order to get seismic indexes liable to comparison. 
Tsuboi ("2) has questioned the theoretical validity of the $N(M)$ relation on the ground that "if we know"

$$
\log N=a+b M
$$

aplies for a certain area and

$$
\log N^{\prime}=a^{\prime}+b^{\prime} M
$$

for another, and if we combine the two areas together into one set of statisties, $\log \left(X+N^{\prime}\right)$ cannot be expressed by a relation which is linear with respect to $1 /$ any more". Nevertheless, it is very known that in the practice $\left({ }^{23}\right)$ :

$$
\log \left(N+N^{\prime}\right)=a^{\prime \prime}+b^{\prime \prime} M .
$$

Accepting the evidence found so far that for shallow shocks the average $b$ is constant, i.e. $b \approx b^{\prime} \approx b^{\prime \prime}$ and adding the equations [1] and $[\because]$, we get:

$$
N+N^{\prime}=10^{a+b .3}+10^{a^{\prime}+b .11}=10^{b .11}\left(10^{\prime \prime}+10^{a^{\prime}}\right),
$$

and:

$$
\log \left(N+N^{\prime}\right)=\left(a+a^{\prime}\right)+b M .
$$

This points ont that the $N(M)$-relation permits superposition in case $b=$ const., as it was assmmed in our previous calculations.

The technique for determining and mapping the seismicity applied by J. V. Riznichenco and I. I. Nersesov $\left({ }^{2-4}\right)$ is based on the idea of approximately constant slopes of occurrence graphs $(\gamma:=0.43 \leq 0.05)$. The proposed method for determining the earthquake risk is based on the idea that the slope of the occurrence graph depends on the average focal depth of the earthquakes considered. Therefore, the constant a or $c$ of the relations:

$$
\log N=a+b M=c+\gamma \log E,
$$

reduced to a standard area is an appropriate measure of the average seismicity but not a measure of the earthquake risk. The earthquake risk depends not merely on the seismic energy released, but also on the depth of the earthquake focus. Consequently, in comparing the earthquake risk in different regions we must consider earthquakes of about the same focal depth. To do this, we normalize the constant a to a standard slope corresponding to a certain depth range. Considering that the earthquake risk comes from shocks of magnitude greater 
than that of the "once per year" earthquake, an increase of the annual number of shocks below this level produced by the proposed thechnique does not imply an increase of the earthquake risk. The increase or decrease of the anmual number of shocks below the leved of the "once per year" earthquake is associated respectively with a slight decrease or increase of the annual number of shocks above this level. Thus the slight change in the annual number of shocks above the level in question does not affect practically the relative measure of the earthquake risk that comes from shallow shocks.

By increasing the limits of the seismotectonic unit the obtained occurrence graph corresponds to more average conditions. To get the relative measure, i.e. the index of the earthquake risk over each subunit we add to the coefficient $a$ of the average recurrence equation the logarithm of the ratio of the seismic energy released in each subunit to the average seismic energy corresponding to each of them. The indexes of the earthquake risk obtained in this way correspond to the level of the earthquake activity observed in each subunit over the period considered. The advantage of the method lies in the fact that we may obtain fairly reliable recurrence rates for subunits for which the existing data is not sufficient for the construction of the occorrence graph.

The smaller the index of the earthquake risk the longer the return periods of the damaging and destructive shocks. If the return periods of the damaging and destructive shocks for a given region are very long the region practically is earthquake immune. Thus theoretically, all regions of the Earth might be considered over long enough time to be subject to earthquakes of whatever magnitude.

\section{ACKNOWLEU(iMENTS.}

Many thanks are due to Drs. N. Ambrasseys and Y. Karnik who read the paper in manuscript and provided many helpful comments. The author is also indebted to Mr. J. Drakopoulos for checking the calculations.

The research reported in this dormment has been sponsored by the Air Force Office of Scientific Research under contract $\triangle F$ il (052)-80.3 through the European Office of Aerospace Research (OMR), Linited States Air Force, as part of the Advanced Research Projects Agency's Project VLIA-UNIFORA. 


\section{REFERENCES}

(1) Galanopoulos $\Lambda .$, On Mapping of Seismic Activity in Greece. "Ann. di Geof. ", 16, 1, 1p. 37-100, (1963).

$\left({ }^{2}\right)$ Galanopoulos A., Evidence for the Seat of the Strain-producing Forces. "Ann. di Geof.", 18, pl). 399-409, (1965).

$\left({ }^{3}\right)$ Katrnik V., Magnilude, Frequency and Energy of Earlhquales in the European Area. "Travaux de l'Inst. (ieoph. de l'Acad. Tehecoslavique des Sciences", 13, 222, pp. 247-272, (Praha 1966).

(4) Riznicinenco, J. V., On Quantitative Determination and Mapping of Scismic Activily. "Anm. di Geof.", 12, 2, p]). 227-237, (1959).

(5) Mryamuna S., Magnitude.Frequency Relations and its Bearings to Geotectonics. "Proc. Japan Ac.", 38, 1, p). 27-30, (1962).

${ }_{\left({ }^{6}\right)}$ IIAnara K., HaGiwara T., IIgh Sensitivily Tripartile Observation of Matsushiro Earthquales. Part 1. "Bull. Earth. Res. Inst. Univ. 'Tokyo ", 44, 3, pp. 1213.1230, (1966).

(7) PAGE A. R. Jr., Aftershocks and Microafiershocks of the Great Alaska Earthquake of 196\%. Thesis submitted for the degree of Doctor of Philosophy in the Faculty of Pure Science, Columbia University, (1967).

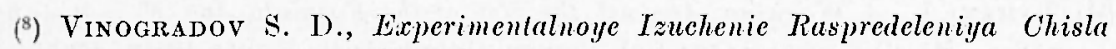
Razryvov po Energii pri Razrushenii Gornylih Porod, "Izvestiya ANSSR, Ser. Geofiz.", 2, p). 171-180, (1962).

$\left({ }^{9}\right)$ Mogi K., Study of Elastic Shocks Caused by the Fracture of Heterogeneous Materials and its Relation to Earthquake Phenomena. "Bull. Earthq. Res. Inst.", 40, p]). 125-173, 831-853, (1962): 41, pp. 615-668, (1963).

${ }^{\left({ }^{10}\right)}$ Karsik V., Magnilude-Frequency Relation and Seismic Activity in Different Regions of the European Area. "Bull. Intern. Inst. Seism. Earthq. Eng.", 1, pp. 9-32, (1964).

(11) Allaen C. R., Amand P. St., Ricitere C. F., Nombquist .I. M., Relationship between Seismicity and Geologic Structure in the Southern California Region. "Bull. Seism. Soc. Am.", 55, 4, pp. 753-797, (1965).

${ }^{(12)}$ Gumbel F. J., Statistics of Extremes. Columbia University Press, New York, (1958).

${ }^{(13)}$ Lonnitz C., Statistical Prediction of Earlhquales. "Reviews of Geophysics", 4, 3, pl. 377-393, (1966).

${ }^{(14)}$ Isacks B., Otuver J., Seismic Waves wilh Frequencies from 1 to 100 cycles per Second Recorded in a Deep Mine in Northern New Jersey. "Bull. Seism. Soc. Am.", 54, 6, p). 1941-1979, (1964).

$\left.{ }^{15}\right)$ Medvedev S. V., An Attempt to malie a New Mapping of the Moldavian Socialist Soviet Republic according to Zones of Seismic Activily. Trans. (Trudy) of the Geophys. Inst. Acad. Sciences ISSR, 5, (1949). 
(16) Kawasumi H., Measures of Earthquake Danger and Expectancy of Maximum Intensity Throughout Japan as Inferred from the Seismic Activity in Historical Times. "Bull. Earthq. Res. Inst. Tokyo", 29, pp. 469. 482, (1951).

(17) Nersesov I. L., Giein V. P., Dzinanuzakov K., On the Seismic Regionalization of the Naryn River Basin, Ed. Acad. Sciences Kirgis, Soc. Sov. Rep., (1960).

(18) Milne G. W., I)ayenport A. ('., Statistical Parameters to Seismic Regionalization. "Proc. and world Conf. Earth. Engin.". 1, III, pp. 181.189, (1965).

(10) Riznicuenco J. V., Calculation of the Tremor Frequenoy at Points on the Earth's Surface due to Earthquakes in their Vicinity. Izvestiya Acad. Sci. USSR, Solid Earth Physics, 5, pp. 287-303, (1966).

(20) Gutenberg B., Ricirter C. F., Seismicity of the Earth and Associated Phenomena. Princeton, N.J., Princeton univ. Press, (1954).

(21) Gutenberg B., The Energy of Earthquakes. Geol. Soc. of London Quarterly Journal, 112, pp. 1-14, (1956).

(22) Tsubor C., On Seismic Activities in and Near Japan. "Contributions in Geophysics in Honour of Gutenberg ", Pergamon Press, pp. 87-112, (1958).

(23) Tамакі I., A Warning Against the Use of the Formula, $\log N=a+b$ $(8-M)$. "Kenzo Sassa Col. Papers, Geoph. Inst. Kyoto Univ. Publ." pp. 555-566, (1963).

(21) Riznichenco J. V., Nersesov I. L., A Detailed Study of the Seismic Regime in the Garm Epicentral Region. "Ann. di Geof.", 14, 2, pp. 173-186, (1961). 